\title{
On the CO Desorption and Absorption in Liquid Low-carbon Steel
}

\author{
Zhuangzhuang LIU, ${ }^{1) *}$ Peter Tom JONES, ${ }^{1)}$ Martin KENDALL, ${ }^{2)}$ Bart BLANPAIN ${ }^{1)}$ and Muxing GUO ${ }^{1)}$ \\ 1) Department of Materials Engineering, KU Leuven, Kasteelpark Arenberg 44, Leuven, BE-3001 Belgium. \\ 2) R \& D Department, Heraeus Electro-Nite Int'I, 1105, Centrum Zuid, Houthalen, B3530 Belgium.
}

(Received on August 27, 2020; accepted on December 9, 2020; J-STAGE Advance published date: January 23, 2021)

\begin{abstract}
$\mathrm{CO}$ absorption and desorption in liquid steel comprise highly significant reaction mechanisms for steelmaking operations such as decarburization, ladle degassing, and the production of rimming steel ingots. However, until present the difference in the mechanism of $\mathrm{CO}$ absorption versus desorption has not been clarified. In this study, the CO desorption and absorption experiments were performed by blowing $\mathrm{Ar}+$ $\mathrm{CO}(0 \%$ and $5 \%$ in volume fraction) gas mixture bubbles into liquid steel with low carbon content (12-19 ppm). The experimental data show that the rate of $\mathrm{CO}$ desorption is much lower than that of absorption. The carbon mass transfer in liquid steel is found to be the rate-limiting step with respect to CO absorption. For $\mathrm{CO}$ desorption, in addition to the carbon mass transfer, the interfacial reaction at the gas-liquid interface is found to pose an additional kinetic barrier. The present finding improves the understanding of the basic $\mathrm{C}-\mathrm{O}$ reaction kinetics involved in many steelmaking processes and contributes to accurate modeling and precise control of industrial practices such as basic oxygen furnace (BOF) and argon oxygen decarburization (AOD)
\end{abstract}

KEY WORDS: CO absorption and desorption; bubble rising model.

\section{Introduction}

Key gas-metal reactions in steelmaking operations comprise the reaction of dissolved carbon and oxygen forming carbon monoxide gas (i.e. CO desorption), as well as the opposite reaction, i.e. carbon monoxide gas absorption by liquid steel. ${ }^{1)}$ For instance, the decarburization of steel in BOF and EAF steelmaking processes can be regarded as essentially involving the reaction $\underline{\mathrm{C}}+\underline{\mathrm{O}} \rightleftharpoons \mathrm{CO}_{(\mathrm{g})}$. The production of rimming steel ingots is influenced by the nucleation of $\mathrm{CO}$ bubbles at the advancing solid-liquid interface. In the argon oxygen decarburization (AOD) practice, due to the $\mathrm{C}-\mathrm{O}$ reaction, the $\mathrm{CO}$ partial pressure in the $\mathrm{Ar}-\mathrm{O}_{2}$ gas bubble can increase with time ${ }^{2)}$ and an enhanced $\mathrm{CO}$ partial pressure can result in the absorption of $\mathrm{CO}$ in the liquid steel durring bubble rising. Thus, a quantitative understanding of the $\mathrm{CO}$ absorption is required to control the $\mathrm{Ar}-\mathrm{O}_{2}$ ratio in the injected gas. Due to its importance, many efforts have been made to understand the rate and mechanisms of the $\mathrm{C}-\mathrm{O}$ reaction. ${ }^{1,3-14)}$ Different experimental methods, such as the Sieverts' test, ${ }^{7,8)}$ the levitated droplet method, ${ }^{5,10,11)}$ the isotope exchange technique ${ }^{3)}$ and the vacuum degassing approach, ${ }^{9)}$ have been employed in $\mathrm{CO}$ absorption and/or desorption studies. In these studies, it is constantly assumed that the $\mathrm{CO}$ absorption and desorption processes are sym-

\footnotetext{
* Corresponding author: E-mail: zhuangzhuang.liu@kuleuven.be
}

metrical, meaning the rate-limit step of the two reactions is the same and the overall reaction rate is equivalent under the same experimental conditions. However, King et al. $\left.{ }^{4}\right)$ observed that for low-carbon steel $(\sim 0.05 \mathrm{wt} \% \mathrm{C})$ the $\mathrm{CO}$ desorption rate was anomalously slower than the absorption rate. The difference in the mechanism of the two processes (CO absorption and desorption) is not yet clearly understood. To avoid incorrect conclusions made by treating $\mathrm{CO}$ absorption and desorption as the same in terms of kinetics, it is essential to re-examine the fundamentals of the two basic reactions, i.e. $\mathrm{CO}$ absorption and desorption in molten steel. Therefore, for the present study, CO absorption and desorption reactions were measured in an induction furnace with approximately $250 \mathrm{~kg}$ of liquid steel. Data obtained in the experiment were analysed. A gas bubble rising model was then constructed to quantify the CO partial pressure evolution in the gas bubble. The rate-limiting step with respect to the $\mathrm{CO}$ desorption and absorption reactions are discussed and conclusions are drawn.

\section{Experimental Principle and Procedure}

The experimental method is based on a submersed probe measurement. Figure 1 shows a schematic drawing of the probe for the measurement of $\mathrm{CO}$ desorption and absorption in liquid low-carbon steel. An induction furnace (Inductotherm, Elphiac) was used for the experiment. Approximately 


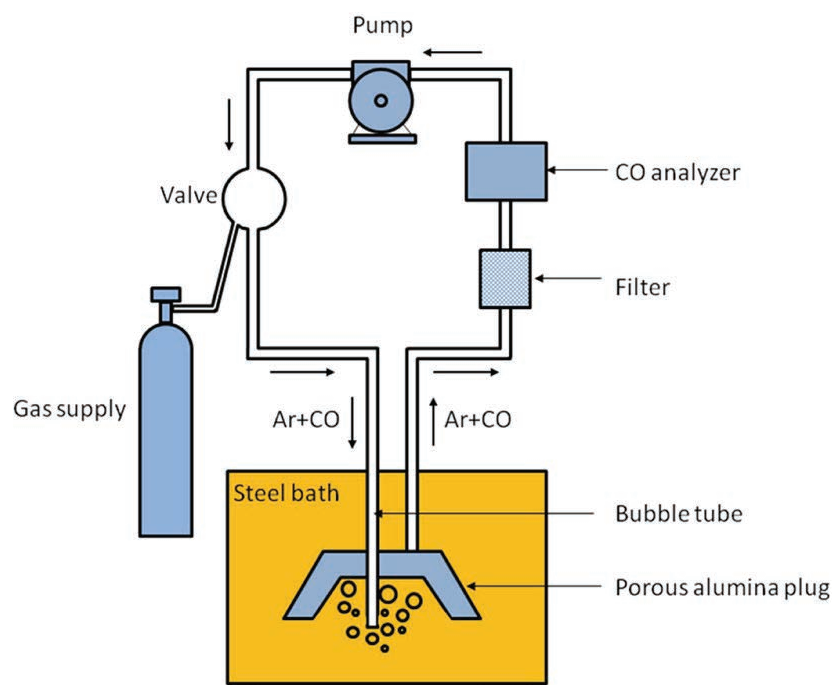

Fig. 1. Experimental set-up for the $\mathrm{CO}$ absorption and desorption measurement. (Online version in color.)

$250 \mathrm{~kg}$ of steel was loaded in a magnesia $(\mathrm{MgO})$ crucible and melted at $1600^{\circ} \mathrm{C}$ in the furnace. A defined volume of gas was injected into the melt through the submersed probe. Argon carrier gas containing 0 and 5 vol\% CO was employed, for respectively the desorption and the absorption tests by the same liquid steel. The off-gas was collected in a porous (gas permeable) alumina plug and pumped through the closed circuit measuring system. A CO analyser measured the final $\mathrm{CO}$ content in the collected gases. ${ }^{15)}$ After measuring for around 20 to 60 seconds, the probe was removed from the molten steel and quenched in a stream of nitrogen. After each measurement, oxygen in the molten steel was examined by solid oxide electrolyte ${ }^{16,17)}$ and a metal sample was taken for compositional analysis (e.g. carbon content) using spark atomic emission spectrometry. After the stabilization of the oxygen content, a new measurement with the $\mathrm{Ar}+\mathrm{CO}$ injection was performed. The curves of recollected carrier gas pressure and the carbon content were recorded via the processor. The steel samples containing 12 to $19 \mathrm{ppm} \mathrm{C}$ and 296 to 569 ppm O were used in this work.

\section{Results and Discussions}

\subsection{Experimental Results}

The experimental conditions and the measured results are shown in Table 1. In each experiment, CO absorption and desorption tests were performed by injecting Ar gas with, respectively, 5 vol $\%$ and 0 vol. $\%$ CO. The experiment was repeated 7 times (heat No. T1-T7) at a temperature of $1570 \pm 3^{\circ} \mathrm{C}$.

\subsection{Behavior of CO Desorption and Absorption}

The dissolved carbon and oxygen in molten steel to form carbon monoxide and, alternatively, $\mathrm{CO}$ disassociation in liquid steel occur as expressed in Eq. (1):

$$
\underline{\mathrm{C}}+\underline{\mathrm{O}} \rightleftharpoons \mathrm{CO}_{(\mathrm{g})}
$$

with equilibrium constant $K$ :

$$
\log K=\log \left(P_{c o} /\left(a_{c} . a_{o}\right)\right)=4887 / T+8.66 \mathrm{~kJ} / \mathrm{mol}^{1}{ }^{1)} \ldots
$$

Table 1. The initial conditions and measured results for the $\mathrm{CO}$ adsorption and desorption tests.

\begin{tabular}{cccccccc}
\hline Heat No. & $\begin{array}{c}T \\
\left({ }^{\circ} \mathrm{C}\right)\end{array}$ & $\begin{array}{c}a_{o} \\
(\mathrm{ppm})\end{array}$ & $\begin{array}{c}a_{c} \\
(\mathrm{ppm})\end{array}$ & $\begin{array}{c}\phi_{a b s}^{o} \\
(\mathrm{vol} \%)\end{array}$ & $\begin{array}{c}\phi_{\text {abs }}^{\tau} \\
(\mathrm{vol} \%)\end{array}$ & $\begin{array}{c}\phi_{\text {des }}^{o} \\
(\mathrm{vol} \%)\end{array}$ & $\begin{array}{c}\phi_{\text {des }}^{\tau} \\
(\mathrm{vol} \%)\end{array}$ \\
\hline $\mathrm{T} 1$ & 1568 & 561 & 12 & 4.94 & 4.00 & 0 & 0.20 \\
$\mathrm{~T} 2$ & 1571 & 352 & 18 & 4.94 & 3.96 & 0 & 0.15 \\
$\mathrm{~T} 3$ & 1567 & 341 & 19 & 4.94 & 3.80 & 0 & 0.08 \\
$\mathrm{~T} 4$ & 1570 & 296 & 18 & 4.94 & 3.65 & 0 & 0.20 \\
$\mathrm{~T} 5$ & 1574 & 558 & 12 & 4.95 & 4.33 & 0 & 0.10 \\
$\mathrm{~T} 6$ & 1570 & 440 & 12 & 4.95 & 4.07 & 0 & 0.21 \\
$\mathrm{~T} 7$ & 1573 & 569 & 16 & 4.95 & 4.23 & 0 & 0.15 \\
\hline Ave. & 1570 & 445 & 15 & 4.94 & 4.01 & 0 & 0.16 \\
Std. & 3 & 118 & 3 & 0.01 & 0.23 & 0 & 0.05 \\
\hline
\end{tabular}

$\phi_{a b s,}^{o}, \phi_{d e s}^{o}$ : initial $\mathrm{CO}$ concentration in $\mathrm{Ar}+\mathrm{CO}$ gas mixture for the $\mathrm{CO}$ absorption and desorption test, respectively.

$\phi_{a b s}^{\tau}, \phi_{d e s}^{\tau}$ : final $\mathrm{CO}$ concentration in the collected $\mathrm{Ar}+\mathrm{CO}$ gas mixture for the $\mathrm{CO}$ absorption and desorption test, respectively.

$a_{c}$ and $a_{o}$ : the activities of $\mathrm{C}$ and $\mathrm{O}$ in the liquid steel and they are considered/assumed to be equivalent to $\mathrm{wt} \% \mathrm{C}$ and $\mathrm{wt} \% \mathrm{O}$, respectively, at low solute concentrations.

where $P_{c o}$ is the partial pressure of carbon monoxide in atmosphere; the activities $a_{c}$ and $a_{o}$ are taken equivalent to $\mathrm{wt} \% \mathrm{C}$ and $\mathrm{wt} \% \mathrm{O}$, respectively, at low solute concentrations with $1 \mathrm{wt} \%$ as reference states. In order to compare the extent of the $\mathrm{CO}$ desorption and absorption reactions, the reaction degree $R$ is defined as:

$$
R=\frac{\phi^{o}-\phi^{\tau}}{\phi^{o}-\phi^{e}}
$$

where $\phi^{o}, \phi^{\tau}$, and $\phi^{e}$ are the $\mathrm{CO}$ volume fractions at, respectively, the initial, final and equilibrium stages. $\phi^{o}$ and $\phi^{\tau}$ are measured in the experiment, as shown in Table 1. $\phi^{e}$ can be calculated with Eq. (2) using the initial carbon and oxygen content in the molten steel with the assumption of 1 atm of total gas bubble pressure $\left(\mathrm{P}_{\mathrm{CO}}=\phi^{e} \times 1.013 \times 10^{5} \mathrm{~Pa}\right)$. The reaction degree as a function of oxygen content in liquid steel is shown in Fig. 2. It is clear that neither absorption nor desorption have reached equilibrium. Nevertheless, the absorption reaction is much closer to equilibrium than the desorption during the tests. Data in Fig. 2 indicate that roughly 40 to $70 \%$ of the $\mathrm{CO}$ absorption, but only 2 to $8 \%$ of the $\mathrm{CO}$ desorption has been completed in the experiments.

It is assumed herein that the CO desorption and absorption rates are controlled by oxygen and/or carbon mass transfer in liquid steel. This is reasonable as it is reported in literature ${ }^{18)}$ that the mass transport of gas phase controls the reaction rate when the carbon content is excess of $0.5 \%$ $(0.0015 \%$ in this work). The Gibbs free energy change for the $\mathrm{CO}$ desorption can be calculated using Eq. (4). It can be seen that the driving force for the $\mathrm{CO}$ desorption reaction, at a given temperature, is the difference between the activity product $a_{c} . a_{o}$ in the liquid steel and the one at the liquid/gas interface, as shown in Eqs. (5) and (6):

$$
\Delta G=-R T \ln \frac{a_{C}^{i} a_{O}^{i}}{a_{C}^{m} a_{O}^{m}}=-R T \ln \left(a_{C}^{i} a_{O}^{i}-a_{C}^{m} a_{O}^{m}\right)
$$




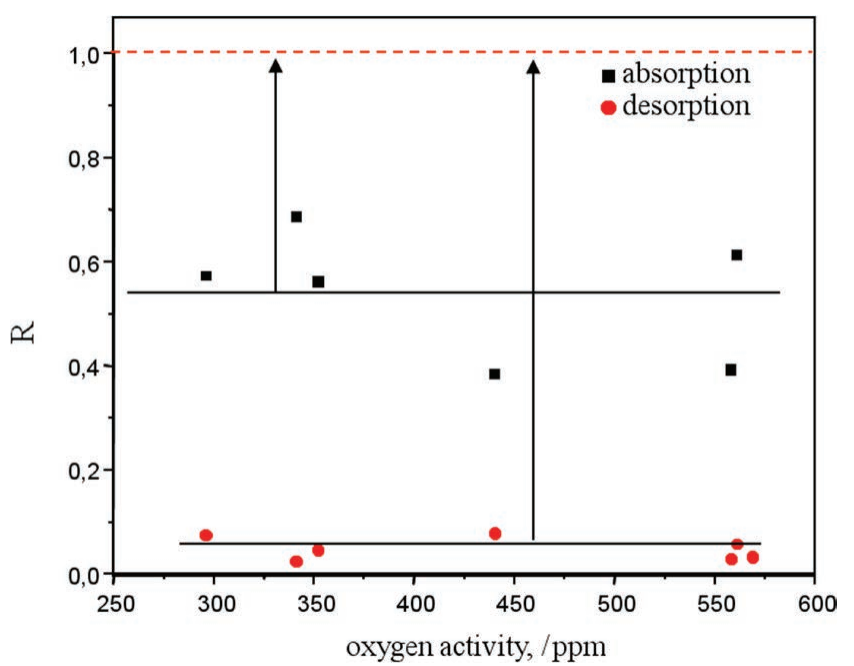

Fig. 2. Reaction degree $R$ of the $\mathrm{CO}$ absorption and desorption. (Online version in color.)

$$
\begin{aligned}
& \Delta E_{\text {des. }}=\left(a_{C}^{m} a_{O}^{m}-a_{C}^{i} a_{O}^{i}\right) \\
& \Delta E_{\text {abs. }}=\left(a_{C}^{i} a_{O}^{i}-a_{C}^{m} a_{O}^{m}\right)
\end{aligned}
$$

where $\Delta E_{\text {des }}$ and $\Delta E_{a b s}$ represent the activity product difference between bulk liquid melt and liquid/gas interface in the desorption and the absorption, respectively; $a_{c}{ }^{m}$ and $a_{o}{ }^{m}$ are the activities of initial carbon and oxygen in the bulk metal, respectively; $a_{c}{ }^{i}$ and $a_{o}{ }^{i}$ are the activities of the carbon and oxygen at gas/metal interface, respectively, which are in equilibrium with the initial $\mathrm{CO}$ concentration in the argon gas bubble. Since the surface reaction is very fast, the activity product $a_{C}^{i} a_{O}^{i}$ can be calculated through Eq. (2) with the measured temperature and the initial $\mathrm{CO}$ concentration in the carrier gas.

The amount of the absorbed CO ( $\phi_{a b s}^{\tau}-\phi_{a b s}^{o}$ in Table 1) and the desorbed ( $\phi_{\text {des }}^{\tau}-\phi_{\text {des }}^{o}$ in Table 1) $\mathrm{CO}$ for the present tests are highlighted in Fig. 3 as a function of the driving force (i.e. activity product difference $\Delta E_{\text {des }}$ and $\Delta E_{a b s}$ ). As seen in Fig. 3, the absorbed $\mathrm{CO}$ increases with the driving force, whereas that of the desorbed $\mathrm{CO}$ is independent of the driving force. This suggests that CO absorption is, indeed, controlled by $\mathrm{O}$ and/or $\mathrm{C}$ mass transfer and an additional kinetic barrier may exist for the $\mathrm{CO}$ desorption.

\subsection{Modeling of CO Desorption/absorption from Liq- uid Steel}

In order to further understand the kinetics of the $\mathrm{C}-\mathrm{O}$ reaction during bubble rising in the liquid steel and to clarify the low reaction degree in this test, a bubble rising model in the liquid steel was constructed.

\subsubsection{Physical Mechanism}

When liquid steel is subjected to a stirring treatment with argon gas, the dissolved carbon can react with dissolved oxygen to form carbon monoxide, owing to the low partial pressure of $\mathrm{CO}$ gas in the rising gas bubble, as demonstrated in Fig. 4(a). On the contrary, if the CO partial pressure in the argon gas bubble is higher than the equilibrium value with the carbon and oxygen in the liquid steel, the $\mathrm{CO}$ in the bubble can dissolve in the liquid steel and diassociate into carbon and oxygen, as shown in Fig. 4(b). The overall

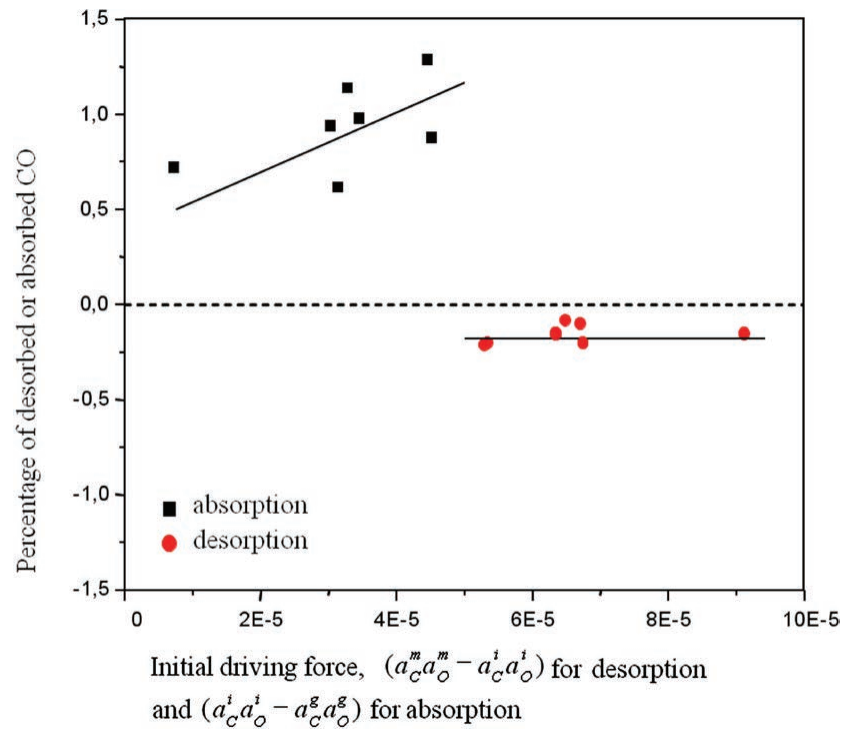

Fig. 3. Influence of driving force on the absorption and desorption reactions. (Online version in color.)

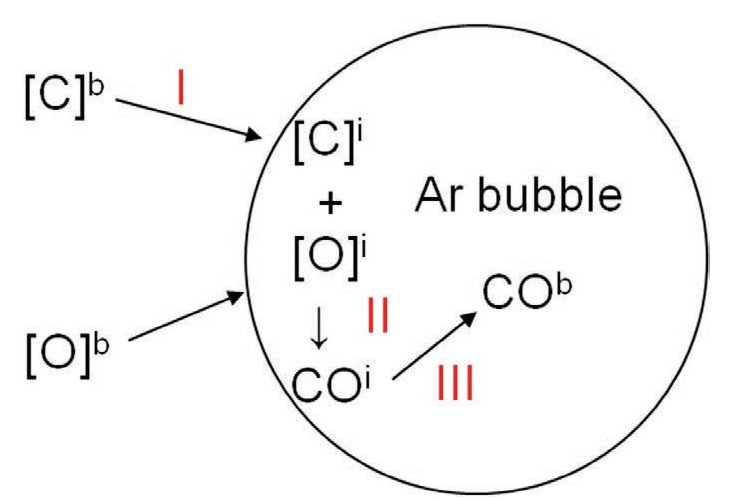

(a)

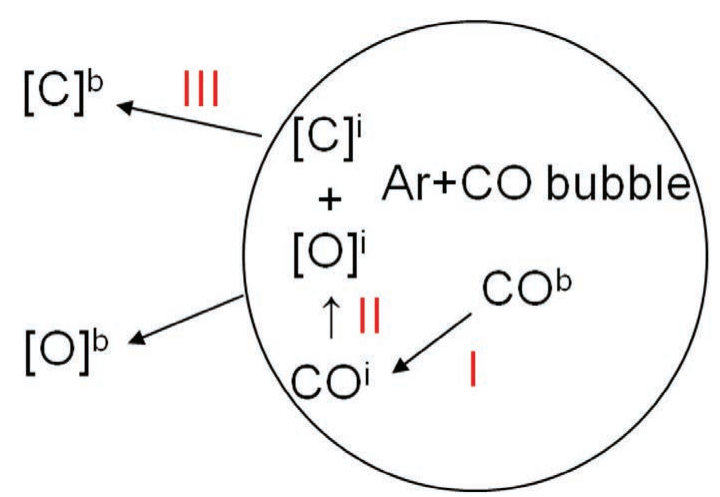

(b)

Fig. 4. Mechanism of CO (a) desorption and (b) absorption from molten steel by blowing Ar or Ar + CO bubble. (Online version in color.)

reactions of $\mathrm{CO}$ desorption/absorption can be broken down into several steps and any one or a combination of these steps can constitute the rate-controlling step (Fig. 4):

I. Transport of dissolved carbon and oxygen from bulk metal (desorption) to the molten steel/argon bubble interface or transport of $\mathrm{CO}$ from bulk gas to the interface (absorption):

CO desorption: $[\mathrm{C}]^{\mathrm{b}} \rightarrow[\mathrm{C}]^{\mathrm{i}},[\mathrm{O}]^{\mathrm{b}} \rightarrow[\mathrm{O}]^{\mathrm{i}}$

$\mathrm{CO}$ absorption: $[\mathrm{CO}]^{\mathrm{b}} \rightarrow[\mathrm{CO}]^{\mathrm{i}}$ 
II. Chemical reaction between carbon and oxygen at the bubble/steel interface:

CO desorption: $[\mathrm{C}]^{\mathrm{i}}+[\mathrm{O}]^{\mathrm{i}} \rightarrow[\mathrm{CO}]^{\mathrm{i}}$

$\mathrm{CO}$ absorption: $[\mathrm{CO}]^{\mathrm{i}} \rightarrow[\mathrm{C}]^{\mathrm{i}}+[\mathrm{O}]^{\mathrm{i}}$

III. Transport of $\mathrm{CO}$ gas from the bubble/steel interface into the bulk gas (desorption) or transport of carbon and oxygen from the interface into the bulk metal (absorption):

$\mathrm{CO}$ desorption: $[\mathrm{CO}]^{\mathrm{i}} \rightarrow[\mathrm{CO}]^{\mathrm{b}}$

$\mathrm{CO}$ absorption: $[\mathrm{C}]^{\mathrm{i}} \rightarrow[\mathrm{C}]^{\mathrm{b}},[\mathrm{O}]^{\mathrm{i}} \rightarrow[\mathrm{O}]^{\mathrm{b}}$

\subsubsection{Estimation of the Rate of CO Formation}

In the present calculation, it is assumed that an argon bubble with a constant volume $V_{g}\left(\mathrm{~m}^{3}\right)$ passes through a molten steel (containing carbon and oxygen) bath at $1570^{\circ} \mathrm{C}$ (Table 1). According to the literature, ${ }^{9)}$ the ratelimiting step of the $\mathrm{C}-\mathrm{O}$ reaction in liquid steel shifts from oxygen-transfer control to carbon-transfer control when $[\mathrm{wt} \% \mathrm{C}] /[\mathrm{wt} \% \mathrm{O}]<0.52$. As in the present experiment, the largest $[\mathrm{wt} \% \mathrm{C}] /[\mathrm{wt} \% \mathrm{O}]$ ratio is 0.06 (calculated from Table 1), it is believed that the overall reaction rate in this test is controlled by carbon mass transfer (interfacial reaction is assumed to be fast and will be discussed later). As a consequence of mass balancing, the molar rate of $\mathrm{CO}$ formation in the Ar bubble equals that of the dissolved carbon transfer from bulk metal to the molten steel/argon bubble interface:

$$
-\frac{d n_{c}^{m}}{d t}=\frac{d n_{c o}^{g}}{d t}=\frac{V_{g}}{R T} \frac{d p_{c o}^{g}}{d t}=A k_{c}\left(C_{c}^{m}-C_{c}^{i}\right)
$$

where $n_{c}{ }^{m}$ and $n_{c o}{ }^{g}$ represent, respectively, the mole number of carbon (in the bulk metal) and carbon monoxide (in the bulk Ar bubble); $V_{g}$ is the volume of the argon gas bubble $\left(\mathrm{m}^{3}\right)$, which is assumed to be constant during bubble rising; $T$ is the temperature $(\mathrm{K}) ; p^{g}{ }_{c o}$ is the partial pressure of $\mathrm{CO}$ gas in the bulk of the Ar bubble; $A$ is the area of the bubble/steel interface $\left(\mathrm{m}^{2}\right) ; C_{c}{ }^{m}$ and $C_{c}{ }^{i}$ are, respectively, the concentration of carbon in the bulk metal and at the bubble/steel interface $\left(\mathrm{mol} / \mathrm{m}^{3}\right) ; k_{c}$ is the mass transfer coefficient of carbon in the molten steel.

Assuming that the chemical reaction at the interface at elevated temperature is fast, the local equilibrium can be reached at the steel/bubble interface. Taking into consideration the rapid transport of $\mathrm{CO}$ in the bulk argon bubble and that of dissolved oxygen in the liquid steel, Eq. (7) can be arranged as:

$$
\frac{d p_{c o}^{g}}{d t}=R T \frac{A}{V_{g}} k_{c}\left(C_{c}^{m}-\frac{p_{c o}^{g}}{K C_{o}^{m}}\right)
$$

where $\mathrm{K}$ is the equilibrium constant which can be obtained from Eq. (2), $C_{o}^{m}$ is the oxygen molar concentration in the liquid steel. From the mass balance, the molar concentration of carbon is related to the wt $\%$ of carbon by:

$$
C_{c}^{m}=\frac{[\mathrm{wt} \% \mathrm{C}] \rho}{100 M_{c}}
$$

where $\rho$ is density of liquid steel, $M_{C}$ is the mole quantity of carbon. Given that $\rho$ is $7.2 \times 10^{3} \mathrm{~kg} / \mathrm{m}^{3}$ and $M_{C}$ is $12 \times$ $10^{-3} \mathrm{~kg} / \mathrm{mol}$, Eq. (9) becomes:

$$
C_{c}^{m}=6000[\mathrm{wt} \% \mathrm{C}]
$$

Inserting Eq. (10) into Eq. (8), the rate of CO evolution in Ar gas bubble can be expressed as:

$$
\frac{d p_{c o}^{g}}{d t}=6000 R T \frac{A}{V_{g}} k_{c}\left([w t \% C]-\frac{p_{c o}^{g}}{K[w t \% O]}\right) \ldots
$$

By intergrating Eq. (11) from $t=0$ to reaction time $t$, the following equation is derived:

$$
\ln \frac{[w t \% C]-\frac{p_{c o}^{o}}{K[w t \% O]}}{[w t \% C]-\frac{p_{c o}^{t}}{K[w t \% O]}}=\frac{6000 R T A}{K V_{g}} k_{c} \frac{t}{[w t \% O]} \ldots \ldots . .
$$

where $p_{c o}^{o}$ and $p_{c o}^{t}$ are initial CO partial pressure $(t=0)$ and the CO partial pressure at time $t$ in the argon bubble, respectively. The gas/liquid interfacial area $A$ and gas volume $V_{g}$ can be expressed as the function of the bubble radius $r$ and assuming that the total pressure in gas bubble is $1 \mathrm{~atm}, \mathrm{Eq}$. (12) becomes:

$$
\begin{aligned}
& p_{c o}^{t}=\frac{p_{c o}^{o}}{\alpha}+K[w t \% O][w t \% C] \frac{(\alpha-1)}{\alpha} \ldots \ldots \ldots \ldots . \\
& \alpha=\exp \left(\frac{18000 R T}{K r} k_{c} \frac{t}{[w t \% O]}\right) \\
& p_{c o}^{t}=p_{c o}^{e}+\frac{1}{\alpha}\left(p_{c o}^{o}-p_{c o}^{e}\right) \\
& \phi^{t}=\phi^{e}+\frac{1}{\alpha}\left(\phi^{o}-\phi^{e}\right)
\end{aligned}
$$

where $p_{c o}^{\mathrm{e}}$ is the $\mathrm{CO}$ partial pressure at equilibrium with the liquid steel with the average initial carbon and oxygen content shown in Table 1; $\phi^{t}$ is the volume fraction of $\mathrm{CO}$ in argon gas bubble at time $t ; k_{c}=5.0 \times 10^{-4} \mathrm{~m} / \mathrm{s}^{9}$ ) (measured by Suzuki and Mori at $[\mathrm{wt} \% \mathrm{O}]=0.06$ and $T=1580^{\circ} \mathrm{C}$, which is close to the present condition, see Table 1). Equations (14) and (15) can be used to evaluate the rate of $\mathrm{CO}$ (carbon and oxygen) evolution by blowing an $\mathrm{Ar} / \mathrm{Ar}+$ $\mathrm{CO}$ bubble with a radius of $r$ into the liquid steel with a certain content of dissolved carbon and oxygen at reacting time $t$ (bubble rising time). As seen from Eq. (15), CO desorption occurs when $p_{c o}^{o}<p_{c o}^{\mathrm{e}}$ and $\mathrm{CO}$ absorption takes place when $p_{c o}^{o}>p_{c o}^{\mathrm{e}}$. In the case of $p_{c o}^{o}=p_{c o}^{\mathrm{e}}$, an equilibrium between $\mathrm{CO}$ in the Ar bubble and carbon and oxygen content in the liquid steel is established, and no apparent $\mathrm{CO}$ absorption and desorption will occur.

Figure 5 shows a typical example of the calculation based on Eqs. (14) and (16), where we assume argon bubble size $r=0.005,0.01,0.02,0.03,0.04$ and $0.05 \mathrm{~m}$, respectively, and take the initial carbon and oxygen content in the steel as $[\mathrm{wt} \% \mathrm{C}]=0.0015,[\mathrm{wt} \% \mathrm{O}]=0.045$ (Table 1). It is clear that for a given steel composition and temperature, $\mathrm{CO}$ evolution is significantly dependent on the Ar bubble size. A small bubble size can result in a large $\mathrm{CO}$ volume fraction (i.e. partial pressure) in the Ar bubble for the same residence time. According to Eq. (16), $\phi^{\circ}$ is known as the initial $\mathrm{CO}$ volume fraction before injection to molten steel and $\phi^{e}$ can be calculated based on steel composition and temperature through Eq. (2). Using the measured CO volume fraction in the collected gas as $\phi^{\mathrm{t}}$, the corresponding bubble residence time $t$ can be calculated via Eqs. (14) and (16). As shown in Fig. 5(a), in the CO absorption test, the 


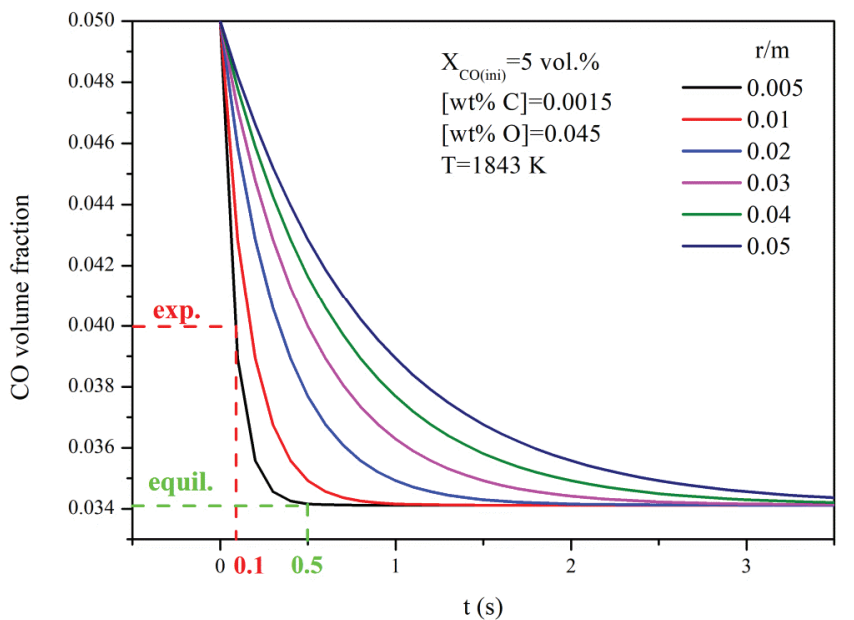

(a)

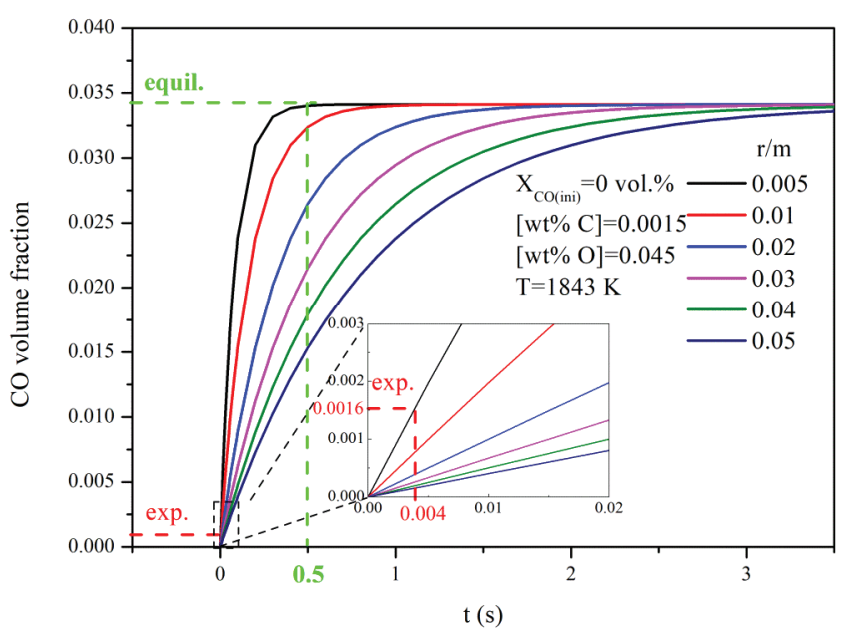

(b)

Fig. 5. Evolution of volume fraction of $\mathrm{CO}$ in an argon bubble with different bubble size. The calculation is based on an average initial carbon and oxygen content in the steel as shown in Table 1. (a) Initial CO volume fraction $=5 \%$ (absorption), (b) initial CO volume fraction $=0 \%$ (desorption). (Online version in color.)

measured $\mathrm{CO}$ volume fraction in the collected gas is 0.04 and the bubble residence time at $r=5 \mathrm{~mm}$ is calculated as $0.1 \mathrm{~s}$ with the bubble rising model. However, in order to reach the reaction equilibrium, a minimum residence time of $0.5 \mathrm{~s}$ is required. This explains the low reaction degree in the present $\mathrm{CO}$ absorption test. However, in the CO desorption measurement, the calculated bubble residence time (CO volume fraction in the off-gas is 0.0016 ) is roughly two orders of magnitude $(0.004 \mathrm{~s})$ lower than that in the $\mathrm{CO}$ absorption test $(0.1 \mathrm{~s})$, as shown in Fig. 5(b). Considering that the two tests ( $\mathrm{CO}$ desorption and absorption) were performed with the same lance (same diameter) at the same immersion depth in the molten steel, it is not reasonable to have such a big bubble residence time difference in these two tests. Hence, in the $\mathrm{CO}$ desorption process, merely considering the elemental diffusion as the rate-limiting step is not appropriate. An additional kinetic barrier may exist in the $\mathrm{CO}$ desorption reaction.

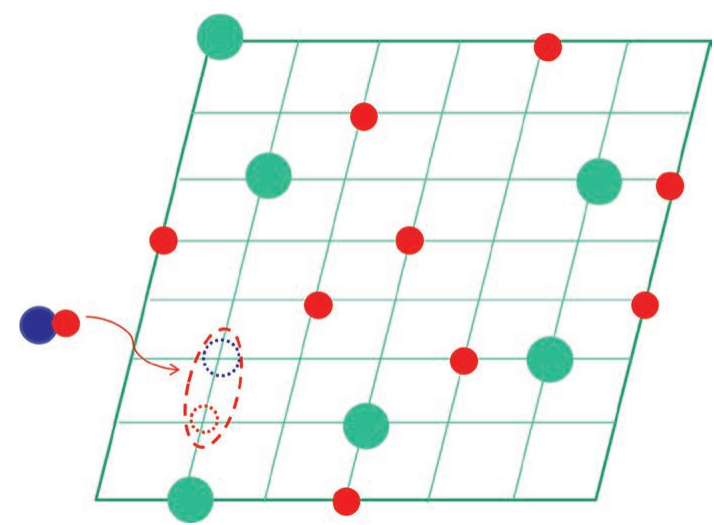

(a)

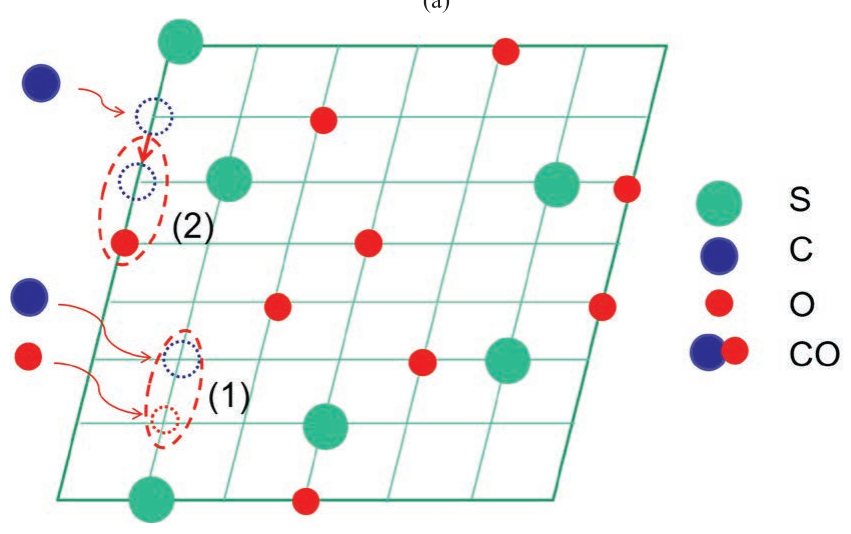

(b)

Fig. 6. The difference of interfacial reaction between (a) $\mathrm{CO}$ absorption and (b) $\mathrm{CO}$ desorption processes. (Online version in color.)

For the $\mathrm{CO}$ absorption reaction $\left(\mathrm{CO}_{(\mathrm{g})} \rightarrow \underline{\mathrm{C}}+\underline{\mathrm{O}}\right), \mathrm{CO}$ molecules at the gas-liquid interface might easily disassociate into carbon and oxygen atoms, as long as there are enough available sites at the surface (Fig. 6(a)). It is reasonable to assume that there are much more available sites than the occupied sites by surface reactants, considering the limited oxygen and sulfur content in the steel. Moreover, as the attractive intermolecular force in liquid phase is much larger than that in gaseous phase, the absorbed carbon and oxygen atoms at the interface can easily diffuse into the liquid side.

However, for $\mathrm{CO}$ desorption $\left(\underline{\mathrm{C}}+\underline{\mathrm{O}} \rightarrow \mathrm{CO}_{(\mathrm{g})}\right)$, the carbon and oxygen atoms in the liquid steel firstly need to be absorbed at the interface. If the carbon and oxygen atoms are next to each other, they could react to form $\mathrm{CO}$, which corresponds to case (1) in Fig. 6(b). However, if the absorbed carbon and oxygen atoms at the interface are far away from each other, as shown in case (2) (Fig. 6(b)), the atoms need to migrate to the site next to the other atom in order to initiate the $\mathrm{C}-\mathrm{O}$ reaction. The migration may be even made more difficult when the sites in between the carbon and oxygen atoms are occupied by surface active elements such as sulfur. Furthermore, the formed $\mathrm{CO}$ at the gas-liquid interface is difficult to detach from the interface and diffuse into the gas phase as there is much larger attractive force from the liquid side. The low probability of occupying the neighboring two sites, difficulties in atom migration, and larger attractive force from the liquid phase in the $\mathrm{CO}$ desorption process jointly contribute to the lower reaction rate than that of the $\mathrm{CO}$ absorption reaction.

Thus, in the $\mathrm{CO}$ desorption in the present low-carbon 
steel, the overall reaction rate may be controlled by both the interfacial chemical reaction and carbon diffusion in the liquid steel, whereas in the $\mathrm{CO}$ absorption process, merely the diffusion in the liquid steel constitutes the rate-limiting step.

\section{Conclusions}

To investigate the $\mathrm{CO}$ absorption and desorption processes in molten steel and obtain an in-depth understanding of the essential $\mathrm{C}-\mathrm{O}$ reaction in the steelmaking process, $\mathrm{Ar}+$ $\mathrm{CO}(0$ and 5 vol.\%) mixtures were injected into the liquid steel through an immersed probe. A gas bubble rising model was constructed to understand the $\mathrm{CO}$ absorption/desorption process. The following conclusions are obtained:

(1) In the present experiments, neither the $\mathrm{CO}$ absorption nor the desorption reaches equilibrium, as a result of the too short bubble residence time in the liquid steel. Nevertheless, the absorption is closer to equilibrium than the desorption. Roughly 40 to $70 \%$ of the $\mathrm{CO}$ absorption and 2 to $8 \%$ of the $\mathrm{CO}$ desorption were completed in the present tests.

(2) The experimental data suggest that at low carbon content (12-19 ppm in this work), the rate of the CO desorption is much slower than that of the absorption. Our results are congruent with $\mathrm{CO}$ absorption being controlled by carbon mass transfer, whereas for $\mathrm{CO}$ desorption the interfacial reaction at the gas-liquid interface seems to be rate-controlling. This finding provides a new insight into the kinetics of the basic $\mathrm{C}-\mathrm{O}$ reaction involved in many steelmaking processes and helps to better control the industrial operations such as controlling carefully the $\mathrm{Ar}-\mathrm{O}_{2}$ ratio in the injected gas during AOD process.

\section{REFERENCES}

1) E. T. Turkdogan: Physical Chemistry of High Temperature Technology, Academic Press, New York, (1980), 51

2) Y. Kishimoto, K. Taoka and S. Takeuchi: Kawasaki Steel Tech. Rep., (1997), No. 37, 51

3) R. Fruehan and S. Antolin: Metall. Trans. B, 18 (1987), 415.

4) G. R. Belton and W. L. Worrell: Heterogeneous Kinetics at Elevated Temperatures: Proc., Plenum Publishing Corporation, New York, (1970), 409

5) P. Distin, G. Hallett and F. Richardson: J. Iron Steel Inst., 206 (1968), 821.

6) S. Whiteway, R. Peters, W. Jamieson and C. Masson: Can. Metall. Q., 7 (1968), 211.

7) M. Solar and R. Guthrie: Metall. Mater. Trans. B, 3 (1972), 713

8) H. Schenck, E. Steinmetz and R. Thielmann: Arch. Eisenhuttenwes., 42 (1971), 79.

9) K. Suzuki and K. Mori: Trans. Iron Steel Inst. Jpn., 17 (1977), 136.

10) K. Ito, K. Amano and H. Sakao: Trans. Iron Steel Inst. Jpn., 17 (1977), 685

11) V. Brabie: Scand. J. Metall., 25 (1996), 148.

12) K. Schwerdtfeger: Arch. Eisenhuttenwes., 54 (1983), 87.

13) T. Emi, W. Boorstein and R. Pehlke: Metall. Trans., 5 (1974), 1959.

14) B. Deo and R. Boom: Fundamentals of Steelmaking Metallurgy, Prentice-Hall, New York, (1993), 21.

15) A. Lob, D. Senk and B. Hallstedt: Steel Res. Int., 82 (2011), 108.

16) R. Fruehan, L. Martonik and E. Turkdogan: Trans. Metall. Soc. AIME, 245 (1969), 1501.

17) E. Turkdogan and R. Fruehan: Can. Metall. Q., 11 (1972), 371.

18) D. Widlund, D. S. Sarma and P. G. Jonsson: ISIJ Int., 46 (2006), 1149 . 